\title{
The effect of baking and frying on the nutritional composition of mackerel
}

\author{
Beibei Duan, Jung-Ah Shin, Ki-Teak Lee* \\ Department of Food Science and Technology, Chungnam National University, Daejeon 34134, Korea
}

\begin{abstract}
The nutritional properties of mackerel are strongly influenced by different cooking methods that can change its nutritional contents. In this study, we investigated the effects of two types of cooking method (i.e. baking and frying) on water-soluble vitamins $\left(B_{1}, B_{2}\right.$, niacin, and folic acid), fat-soluble vitamins (A and $E$ ), cholesterol, $\beta$-carotene, and minerals $(\mathrm{K}, \mathrm{P}, \mathrm{Mg}, \mathrm{Se}$, and $\mathrm{Zn}$ ) and on the proximate composition of mackerel. Compared to the baked fish, contents of vitamins $A$ and $B 1$ and cholesterol were reduced by $56.52 \%, 59.93 \%$, and $33.40 \%(p<0.05)$, respectively, in the fried fish. On the other hand, vitamin $\mathrm{E}$ and folic acid contents in the fried fish were significantly higher than those in the baked fish $(\mathbf{p}<\mathbf{0 . 0 5})$. Furthermore, niacin was detected only in the baked fish and $\beta$-carotene was found in neither the baked fish nor the fried fish. There was also no significant difference in moisture content between baked and fried fish samples. The fat, carbohydrate, and crude ash contents in fried fish were higher than those in baked fish; however, protein content in fried fish was about $3.73 \%$ lower than that in baked fish. Since different cooking methods have different effects on the nutrients of mackerel, nutritional value of mackerel could be enhanced by selecting the suitable cooking method.
\end{abstract}

Key words : mackerel, baking, frying, fat-soluble vitamins, water-soluble vitamins

\section{Introduction}

Mackerel, which is found near the western coast of the Pacific and Atlantic area (1), is consumed worldwide. Mackerel is abundant in polyunsaturated fatty acids, which have been proven to actively ameliorate cancers and enhance memory (2). Furthermore, mackerel contains several vitamins and minerals, along with cholesterol, which play important functions in the human body. For example, insufficient consumption of niacin and protein can cause pellagra (3), and minerals participate in energy metabolism to maintain the normal functions of muscles and nerves of the human body (4). Cholesterol is involved in the formation of membranes, and is an important component for the synthesis of bile acid, vitamin D, and steroid hormones (5).

*Corresponding author. E-mail : ktlee@cnu.ac.kr Phone : 82-42-821-6729, Fax : 82-42-821-6721

Received 3 May 2018; Revised 5 July 2018; Accepted 16 July 2018.

Copyright (c) The Korean Society of Food Preservation. All rights reserved.
In daily life, fish can be eaten raw, but for better taste, different cooking methods are commonly used, which can have negative or positive effects on the nutritional composition of fish (6). There have already been many studies on the influences of various cooking methods (frying, boiling, steaming, and baking) on the contents of vitamins, mineral, and fatty acids in different types of fish $(7,8)$. Erkan et al. (8) compared the contents of amino acids, vitamins, and other nutrients between raw horse mackerel and that cooked by different methods (frying, grilling, and steaming).

In this study, we analyzed the fat-soluble nutrients (cholesterol, $\beta$-carotene, vitamin $A$, and vitamin $\mathrm{E}$ ), water-soluble vitamins (vitamin $B_{1}, B_{2}$, niacin, and folic acid), and selected minerals, along with the proximate composition (moisture, proteins, lipids, and carbohydrates) of mackerel cooked by two different methods, i.e. baking and frying, and compared the effects of the cooking methods on the nutrient composition of mackerel. 


\section{Materials and methods}

\section{Samples preparation}

Mackerel was purchased from the local market (Jeonju, Korea) and was cooked as follows. Samples were divided into two groups for baking and frying. For the baking process, $20 \mathrm{~g}$ vinegar was added to mackerel $(3,980 \mathrm{~g})$, and the surface of mackerel was baked using a grate for $7 \mathrm{~min}$. In the frying process, mackerel $(3,846 \mathrm{~g})$ was fried in the presence of soybean oil $(577 \mathrm{~g})$ and frying powder $(577 \mathrm{~g})$ at $170-180^{\circ} \mathrm{C}$ for 5-7 min. A food blender was used to homogenize each group of samples, followed by dividing into three batches $(n=3)$ for statistical analysis.

\section{Saponification and solvent extraction}

Alkaline saponification was performed using the National Laboratory System (NLS) method to obtain non-saponifiable compounds like fat-soluble vitamins and cholesterol (9). Homogenized fish samples $(5 \mathrm{~g})$ were weighed and put in $200 \mathrm{~mL}$ extraction tubes followed by adding $10 \mathrm{~mL}$ of $6 \%$ pyrogallol solution (in ethanol). The samples were then vortexed for $2 \mathrm{~min}$ and flushed with nitrogen $(1 \mathrm{~min})$. Afterwards, the samples were sonicated for $10 \mathrm{~min}$, followed by adding $60 \%$ potassium hydroxide $(8 \mathrm{~mL})$, and vortexed for further $2 \mathrm{~min}$, and then flushed with nitrogen $(1 \mathrm{~min})$. The extraction tubes were placed in a water bath at $75^{\circ} \mathrm{C}$ for $1 \mathrm{~h}$ at $100 \mathrm{rpm}$ (shaking water bath, BS-21, Lab Companion, Ramsey, MN, USA). The tubes were then washed two times with $10 \mathrm{~mL}$ sodium chloride solution (in triple-distilled water, $2 \%$ ), and an additional $15 \mathrm{~mL}$ solution (n-hexane:ethyl acetate, 85:15, v/v, BHT 0.01\%) was added for extraction. After vortexing for $2 \mathrm{~min}$, the supernatants were dehydrated through an anhydrous sodium sulfate column, and transferred to other vials. The $15 \mathrm{~mL}$ solution was used to extract lipid twice. The supernatants were all collected in a $50 \mathrm{~mL}$ volumetric flask. The extra solution was then added to the volumetric flask up to $50 \mathrm{~mL}$ and stored at $-20^{\circ} \mathrm{C}$ until analysis.

\section{Determination of fat-soluble vitamins ( $A$ and $E$ )}

Fat-soluble vitamins (A and $\mathrm{E}$ ) were determined according to the NLS procedure with slight modifications (9). Retinol and DL-a-tocapherol were used as standards for vitamin A and vitamin $\mathrm{E}$ quantification, respectively. The HPLC instrument (Yonglin SP930D, Anayang, Korea) for vitamin A determination was equipped with LiChrospher ${ }^{\circledR}$ Diol 100 Column (Merck KGaA, $5 \mu \mathrm{m}, 250 \mathrm{~mm} \times 4 \mathrm{~mm}$, Darmstadt,
Germany) and a fluorescence detector (Ex $\lambda=326 \mathrm{~nm}, \mathrm{Em} \lambda$ $=470 \mathrm{~nm}$ ). The mobile-phase contained iso-propanol and $\mathrm{n}$-hexane $(5: 95 \mathrm{v} / \mathrm{v}, \mathrm{LC}$ grade) and the flow rate was set to $1 \mathrm{~mL} / \mathrm{min}$. Samples $(20 \mu \mathrm{L}$ each) were injected into the column and the analysis was performed for $20 \mathrm{~min}$.

The HPLC instrument for vitamin E determination was equipped with LiChrospher ${ }^{\circledR}$ Diol 100 Column (Merck KGaA, $5 \mu \mathrm{m}, 250 \mathrm{~mm} \times 4 \mathrm{~mm})$ and a fluorescence detector $(\operatorname{Ex} \lambda=290$ $\mathrm{nm}, \operatorname{Em} \lambda=330 \mathrm{~nm}$ ). The mobile-phase contained $\mathrm{n}$-hexane and iso-propanol (99.4:0.6, v/v) and the flow rate was constant at $1.0 \mathrm{~mL} / \mathrm{min}$. Samples $(20 \mu \mathrm{L}$ each) were injected into the column and the analysis was performed for $60 \mathrm{~min}$.

Determination of water-soluble vitamins $\left(B_{1}\right.$, $B_{2}$, niacin, and folic acid)

Contents of the vitamin $\mathrm{B}_{1}, \mathrm{~B}_{2}$, niacin, and folic acid were measured according to the NLS procedure (9).

\section{Determination of cholesterol}

Cholesterol extraction was performed following the NLS procedure (9). A gas chromatograph (YL 6000 series, Yonglin, Anayang, Korea) was equipped with a YL 6100 instrument fitted with an FID detector. An HP-5 (30 m×0.32 $\mathrm{mm}, 0.25 \mu \mathrm{m}$ ) column was used to separate the cholesterol, using nitrogen as the carrier gas at a pressure of $18.4 \mathrm{psi}$ and a flow rate of $0.4 \mathrm{~mL} / \mathrm{min}$. The temperatures of both the detector and injector were set at $300^{\circ} \mathrm{C}$. The oven temperature was set at $285^{\circ} \mathrm{C}$ and the analysis time was 15 min. 5a-Cholestane was used as an internal standard for quantification of cholesterol.

\section{Determination of $\beta$-carotene content}

$\beta$-Carotene content was measured by HPLC according to the NLS procedure (9), using an external calibration curve.

\section{Determination of proximate composition}

Proximate composition analysis was done with three replicates for measuring moisture, fat, protein, carbohydrate, and crude ash contents following the NLS procedure (9).

\section{Statistical analysis}

All the samples were analyzed in triplicate. Significant difference between the samples was statistically evaluated by the Student's t-test. The significant difference was adopted by confidence level of $95 \%(p<0.05)$. 


\section{Results and discussion}

\author{
Fat-soluble vitamins ( $A$ and $E$ ), cholesterol, \\ and $\beta$-carotene
}

Table 1 shows the contents of fat-soluble vitamins (A and E), cholesterol, and $\beta$-carotene in mackerel cooked by different methods. Vitamins A, E, and cholesterol contents of fried fish were found to be $0.010 \pm 0.003 \mathrm{mg} / 100 \mathrm{~g}$, $2.458 \pm 0.042 \mathrm{mg} / 100 \mathrm{~g}$, and $35.361 \pm 2.47 \mathrm{mg} / 100 \mathrm{~g}$, respectively. Compared to baked fish, the contents of vitamin A and cholesterol in fried fish were reduced by $56.52 \%$ and $33.40 \%(\mathrm{p}<0.05)$, respectively. On the other hand, the vitamin E content in fried fish was significantly increased by $275.27 \%$ $(\mathrm{p}<0.05)$.

Table 1. The contents of fat-soluble vitamins (A and E), cholesterol, and $\beta$-carotene in baked and fried mackerel

(unit: $\mathrm{mg} / 100 \mathrm{~g}$ )

\begin{tabular}{ccc}
\hline & \multicolumn{2}{c}{ Cooking method } \\
\cline { 2 - 3 } & Baking & Frying \\
\hline Vitamin A & $0.023 \pm 0.001^{1) \mathrm{a} 2)}$ & $0.010 \pm 0.003^{\mathrm{b}}$ \\
Vitamin E & $0.655 \pm 0.037^{\mathrm{b}}$ & $2.458 \pm 0.042^{\mathrm{a}}$ \\
B-Carotene & $\mathrm{ND}^{3)}$ & $\mathrm{ND}$ \\
Cholesterol & $53.092 \pm 1.220^{\mathrm{a}}$ & $35.361 \pm 2.470^{\mathrm{b}}$ \\
\hline
\end{tabular}

${ }^{1)}$ Results are the mean $\pm S D$ of three measurements.

${ }^{2)}$ All values within a row with different letters are significantly different from each other at $\mathrm{p}<0.05$, as determined by the Student's t-test.

${ }^{3)} \mathrm{ND}$, not detected.

The increased vitamin $\mathrm{E}$ content in fried fish may be due to the use of frying oil during cooking, because commercial frying oil usually contains additional vitamin $\mathrm{E}$, which might have migrated into the fish tissues.

The vitamin A content in fried fish was lower than that in baked fish. Similar results were found in a previous study (10), in which the effect of different cooking methods on the different nutritional qualities of Kutum roach was studied and the content of vitamin $\mathrm{A}$ in fried fish was found to be $33.33 \%$ less than that in baked fish. Since vitamin A is not very stable at high temperatures, some part of vitamin A may have degraded during cooking. The results shown in Table 1 suggest that the frying process has a more significant impact on reducing vitamin A content than the baking process. Similarly, frying reduced the content of cholesterol more compared to baking (Table 1), partly due to the exudation of fish oil containing lipid-soluble substances like cholesterol. For example, relatively heat-stable and lipid soluble compounds like cholesterol were released from fish tissues to the cooking oil while some of the cooking oil was absorbed into the fish during frying. Thus, lower content of cholesterol is expected in fried fish than in baked fish.

In general, $\beta$-carotene is abundant in many vegetables, orange or red fruit chromoplasts (11-12), and some fishes. However, in our study, $\beta$-carotene was found in neither baked fish nor fried fish (Table 1).

Water-soluble vitamins $\left(B_{1}, B_{2}\right.$, niacin, and folic acid)

Fig. 1 shows the effect of baking and frying on vitamin $\mathrm{B}_{1}, \mathrm{~B}_{2}$, niacin, and folic acid contents in mackerel. Compared to baked fish, vitamin $\mathrm{B}_{1}$ content in fried fish decreased by $59.93 \%(p<0.05)$. Similar results were observed in study by Erkan et al. (8), in which the lowest vitamin $\mathrm{B}_{1}$ content in horse mackerel was obtained by frying among the different cooking methods (frying, grilling, and steaming). According to the study by Erkan et al. (8), vitamin $B_{1}$ content decreased from $0.21 \mathrm{mg} / 100 \mathrm{~g}$ in raw fish to $0.042 \mathrm{mg} / 100 \mathrm{~g}$ in fried fish and $0.069 \mathrm{mg} / 100 \mathrm{~g}$ in grilled fish, suggesting that cooking significantly reduced vitamin $\mathrm{B}_{1}$ content and frying led to the maximum reduction in vitamin $B_{1}$ content. Their results also showed that vitamin $\mathrm{B}_{2}$ contents were reduced from $0.144 \mathrm{mg} / 100 \mathrm{~g}$ in raw fish to $0.136 \mathrm{mg} / 100 \mathrm{~g}$ and $0.109 \mathrm{mg} / 100 \mathrm{~g}$ upon frying and grilling, respectively, suggesting that vitamin $\mathrm{B}_{2}$ may be more stable than vitamin $\mathrm{B}_{1}$ during cooking. In our study, vitamin $\mathrm{B}_{2}$ content in baked fish was significantly lowered compared to that in fried fish $(\mathrm{p}<0.05)$ (Fig. 1).

Niacin is also unstable when exposed to high temperatures. Interestingly, niacin was found only in baked fish (Fig. 1)

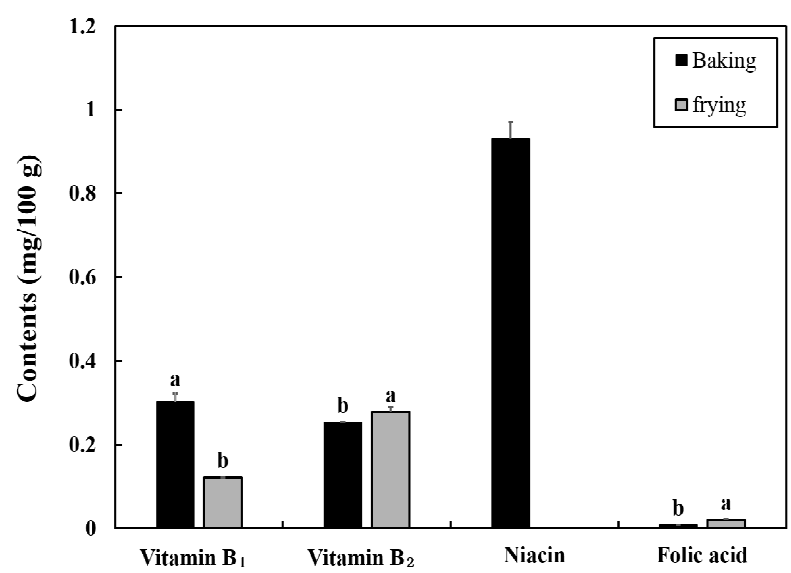

Fig. 1. The contents of water-soluble vitamins (B1, B2, niacin, and folic acid) in baked and fried mackerel.

Results are the mean $\pm \mathrm{SD}$ of three measurements. All values are significantly different from each other at $\mathrm{p}<0.05$, as determined by the Student's t-test. 
probably due to the different heat exposure conditions (time and temperature) of the different cooking methods. Similar results were obtained by Ersoy and Ozeren (13), who reported that niacin content in raw fish was reduced from $1.13 \mathrm{mg} / 100$ $\mathrm{g}$ to $0.04 \mathrm{mg} / 100 \mathrm{~g}$ and $0.73 \mathrm{mg} / 100 \mathrm{~g}$ upon frying and baking, respectively, suggesting that a large amount of niacin is destroyed during the frying process. Meanwhile, the contents of folic acid in both the baked $(6.89 \mu \mathrm{g} / 100 \mathrm{~g})$ and the fried fish $(19.56 \mu \mathrm{g} / 100 \mathrm{~g})$ were relatively low compared with the vitamin $\mathrm{B}_{1}, \mathrm{~B}_{2}$, and niacin contents (Fig. 1).

\section{Mineral contents and proximate composition}

The mineral contents of baked and fried fish samples are presented in Fig. 2. Potassium (K) content was found to be similar in fried fish and baked fish. A similar result was obtained in a previous study on rainbow trout, in which the difference in $\mathrm{K}$ content between fried fish and baked fish was not significant ( $\mathrm{p}>0.05$ ) (14). However, $\mathrm{P}$ and $\mathrm{Zn}$ contents both were found to decrease after baking and frying, with slightly higher levels of $\mathrm{P}$ and $\mathrm{Zn}$ in baked fish than in fried fish (14). The $\mathrm{Mg}$ content of the baked fish was also significantly different from that of the fried one $(p<0.05)$, whereas Se contents of fried and baked fish samples were not significantly different ( $p>0.05$ ). The effects of baking and frying on the contents of moisture, fats, proteins, carbohydrates, and crude ash are shown in Table 2. While moisture content did not change much, the fat, carbohydrate, and crude ash contents were higher in fried fish than in baked fish.

Furthermore, the content of protein $(23.373 \mathrm{~g})$ was found to be higher in baked fish than in fried fish (19.641 g). When

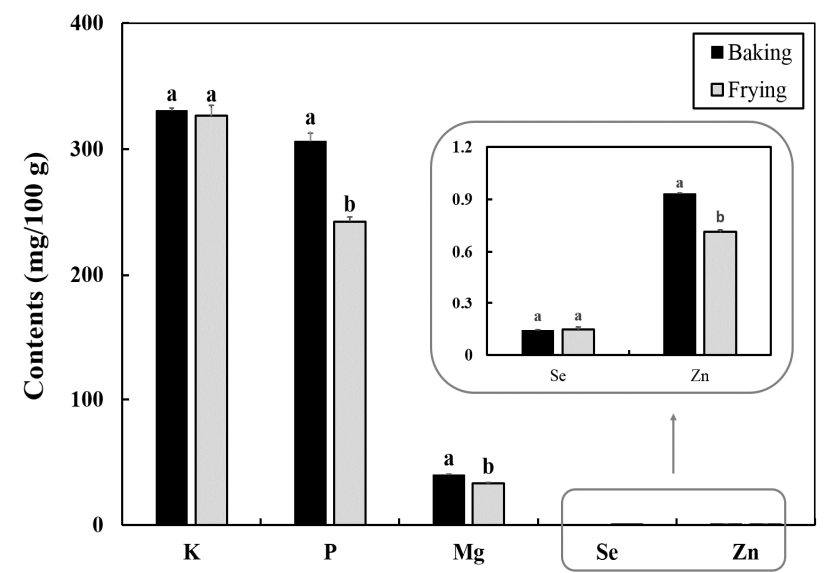

Fig. 2. The mineral contents of baked and fried mackerel. Results are the mean \pm SD of three measurements. All values are significantly different from each other at $\mathrm{p}<0.05$, as determined by the Student's t-test. frying, part of the water is lost by evaporation, followed by osmosis of frying oil into the fish, resulting in higher fat content in fried fish than in baked fish. Similar results were obtained in a previous study, in which has fat content in fried African catfish increased by $2.17 \%$ compared to baked fish (13). Since commercial frying batter usually contains starch and other carbohydrates, fried fish also exhibits higher carbohydrate content than baked fish (Table 2).

Table 2. The proximate compositions of baked and fried mackerel (unit: \%)

\begin{tabular}{ccc}
\hline \multirow{2}{*}{ Proximate composition } & \multicolumn{2}{c}{ Cooking method } \\
\cline { 2 - 3 } & Baking & Frying \\
\hline Moisture & $45.875 \pm 0.280^{1)}$ & $45.743 \pm 0.412$ \\
Fat & $25.687 \pm 0.198$ & $26.172 \pm 1.080$ \\
Protein & $23.373 \pm 0.371$ & $19.641 \pm 0.457$ \\
Carbohydrate & $6.142 \pm 0.235$ & $9.113 \pm 0.352$ \\
Crude ash & $1.281 \pm 0.007$ & $1.344 \pm 0.075$ \\
\hline
\end{tabular}

${ }^{1)}$ Results are the mean \pm SD of three measurements.

\section{Acknowledgment}

This research was supported by a grant (17162식생활082) from Ministry of Food and Drug Safety. We express our gratitude to our colleagues from the NLS who provided expertise.

\section{References}

1. De Vries DA, Grimes CB, Lang KL, White DB (1990) Age and growth of king and Spanish mackerel larvae and juveniles from the Gulf of Mexico and US South Atlantic Bight. Environ Biol Fishes, 29, 135-143

2. Luzia LA, Sampaio GR, Castellucci CMN, Torres EAFS (2003) The influence of season on the lipid profiles of five commercially important species of Brazilian fish. Food Chem, 83, 93-97

3. Ozden O, Erkan N (2008) Comparison of biochemical composition of three aqua cultured fishes (Dicentrarchus labrax, Sparus aurata, Dentex dentex). Int J Food Sci Nutr, 59, 545-557

4. Watanabe T, Kiron V, Satoh S (1997) Trace minerals in fish nutrition. Aquaculture, 151, 185-207

5. Brown DA, London E (2000) Structure and function of 
sphingolipid- and cholesterol-rich membrane rafts. J Biol Chem, 275, 17221-17224

6. Hemre GI, Mommsen TP, Krogdahl A (2002) Carbohydrates in fish nutrition: effects on growth, glucose metabolism and hepatic enzymes. Aquacult Nutr, 8, 175-194

7. Weber J, Bochi VC, Ribeiro CP, Victorio AdM, Emanuelli T (2008) Effect of different cooking methods on the oxidation, proximate and fatty acid composition of silver catfish (Rhamdia quelen) fillets. Food Chem, $106,140-146$

8. Erkan N, Selçuk A, Ozden O (2010) Amino acid and vitamin composition of raw and cooked horse mackerel. Food Anal Methods, 3, 269-275

9. KFDA (2017) NLS Standard Operating Procedure Analytical Methods. Korea Food and Drug Administration, Osong, Korea, p 43-150
10. Hosseini H, Mahmoudzadeh M, Rezaei M, Mahmoudzadeh L, Khaksar R, Khosroshahi NK, Babakhani A (2014) Effect of different cooking methods on minerals, vitamins and nutritional quality indices of kutum roach (Rutilus frisii kutum). Food Chem, 148, 86-91

11. Castenmiller JJ, West CE (1998) Bioavailability and bioconversion of carotenoids. Annu Rev Nutr, 18, 19-38

12. Vishnevetsky M, Ovadis M, Vainstein A (1999) Carotenoid sequestration in plants: the role of carotenoid-associated proteins. Trends Plant Sci, 4, 232-235

13. Ersoy B, Ozeren A (2009) The effect of cooking methods on mineral and vitamin contents of African catfish. Food Chem, 115, 419-422

14. Gokoglu N, Yerlikaya P, Cengiz E (2004) Effects of cooking methods on the proximate composition and mineral contents of rainbow trout (Oncorhynchus mykiss). Food Chem, 84, 19-22 